\title{
Analysis of Electrical Characteristics using a Lambert W-Function Tech- nique and MATLAB Simulation for Dye Sensitised ZnO Solar Cell
}

\author{
Renu Guliani ${ }^{1}$, Amit Jain ${ }^{2}$, Swati Sharma ${ }^{1}$, Davinder Kaur ${ }^{1}$, Akhil Guliani ${ }^{3}$ and Avinashi Kapoor ${ }^{1, *}$ \\ ${ }^{I}$ Department of Electronic Science, University of Delhi South Campus, New Delhi, India \\ ${ }^{2}$ Department of Electronics, Rajdhani College, University of Delhi, New Delhi, India \\ ${ }^{3}$ Department of Instrumentation \& Control, Netaji Subhash Institute of Technology, University of Delhi, India
}

\begin{abstract}
Present article deals with analysis of output characteristics in ZnO based Dye Sensitised Solar Cell (DSSC) using a Lambert W-function technique and MATLAB Simulation. We have used an analytical approach having no approximation for extracting various parameters of DSSC, a well known Lambert W-function technique. The model used in present work is single diode model including the capacitance in equivalent circuit and hence study its effect on currentvoltage characteristics and other DSSC parameters. Results hence obtained are discussed and validated using MATLAB Simulation.
\end{abstract}

Keywords: Dye Sensitised Solar Cell, Lambert W-Function, MATLAB, Electrochemical Impedance Spectroscopy, Simulation.

\section{INTRODUCTION}

DSSC an electrochemical photovoltaic device consist of mesoporous semiconductor wetted with photoactive dye and plunged into a liquid electrolyte [1]. It differs from the conventional solar cell as it separates the function of light absorption from charge carrier transport. So far study of solar cell characteristics was dominated by their static behaviour [2], few attempts have been made to observe the dynamic behaviour of solar cells [3-5]. Capacitance characteristics which give rise to dynamic behavior are unique components of DSSCs arising due to oxide/dye/electrolyte interface of the order of $\mathrm{mF} / \mathrm{cm}^{2}$ [5], while in Si solar cells capacitance of the order of $\mu \mathrm{F} / \mathrm{cm}^{2}$ [6] is due to junction capacitance. Han and Dai $[3,4]$ gave a qualitative approach to study effect of capacitance on DSSC which was further improved by Hanmin et al. [7] when they introduced both qualitative and quantitative analysis for capacitive effect. Han et al. gave detailed impedance analysis using EIS and predicted the capacitive part in internal impedance of DSSC [8,9] Merhej et al. [10] provided a computational simulation technique using MATLAB to study the effect of capacitance on currentvoltage characteristics of solar cells.

Present work takes into account both resistive and capacitive effect while studying DSSCs. Both qualitative and quantitative analysis has been performed to conclude the dominance of capacitance in DSSCs. Capacitive effects in DSSC are investigated and hence a new single diode model having both resistance and capacitance is proposed in DSSC for improving the existing mathematical model [11]. Equivalent circuit of DSSC has been used for analytical analysis

*Address correspondence to this author at the Department of Electronic Science, University of Delhi South Campus, New Delhi, India;

Tel: 91-11-24116178; Fax: 91-11-2411606;

E-mail: avinashi_kapoor@yahoo.com and statistical analysis of the experimental data. For verification of our model we used the accurate solar cell simulator developed by Ishaque et al. [12]. The use of this simulator had an advantage over developing our own as it used a different basic model for the thin film solar cells, hence giving proof of accuracy for our values calculated using our DSSC mathematical model and the statistical analysis of the experimental data.

\section{STATISTICAL ANALYSIS OF THE EXPERIMEN- TAL DATA AND EQUIVALENT CIRCUIT}

\subsection{Preparation of DSSC}

$\mathrm{ZnO}$ nano particles were prepared using Sol-gel technique. Nanoparticles were prepared by dissolving $0.2 \mathrm{M}$ Zinc acetate dehydrate $\left[\mathrm{Zn}\left(\mathrm{CH}_{3} \mathrm{COO}\right)_{2} .2 \mathrm{H}_{2} \mathrm{O}\right]$ in methanol at room temperature. Then this solution was mixed ultrasonically for 2 hours at $25^{\circ} \mathrm{C}$. Transparent and clear solution was obtained. $\mathrm{NaOH}$ was then added for the desired $\mathrm{pH}$ level $(\mathrm{pH}$ 9 ) in the solution. The solution was again stirred ultrasonically for $60 \mathrm{~min}$. The resulting solution was kept undisturbed. Precipitates collected at the bottom were filtered and washed with excess methanol to remove the starting material. Precipitates were dried for $15 \mathrm{~min}$ at $80^{\circ} \mathrm{C}$ on hot plate [13]. The structural and optical properties of synthesized $\mathrm{ZnO}$ nanoparticles were studied. The XRD measurements were carried out using Bruker AXS - D8 discover diffractometer as shown in Fig. (1). XRD showed that average size of $\mathrm{Z}_{\mathrm{n}} \mathrm{O}$ crystalloid particles was $50 \mathrm{~nm}$ and was confirmed by using TECNAI $\mathrm{G}^{2}$ T30, u-TWIN TEM, as shown in Fig. (2).

DSSCs were fabricated using the synthesized powder. The porous $\mathrm{ZnO}$ film was deposited on Indium- tin- oxide (ITO)-coated glass substrate by doctor blade technique. The substrate was cleaned using acetone, methanol and distilled water in sequence in an ultrasonic bath. $\mathrm{ZnO}$ powder(1.2 gm) 


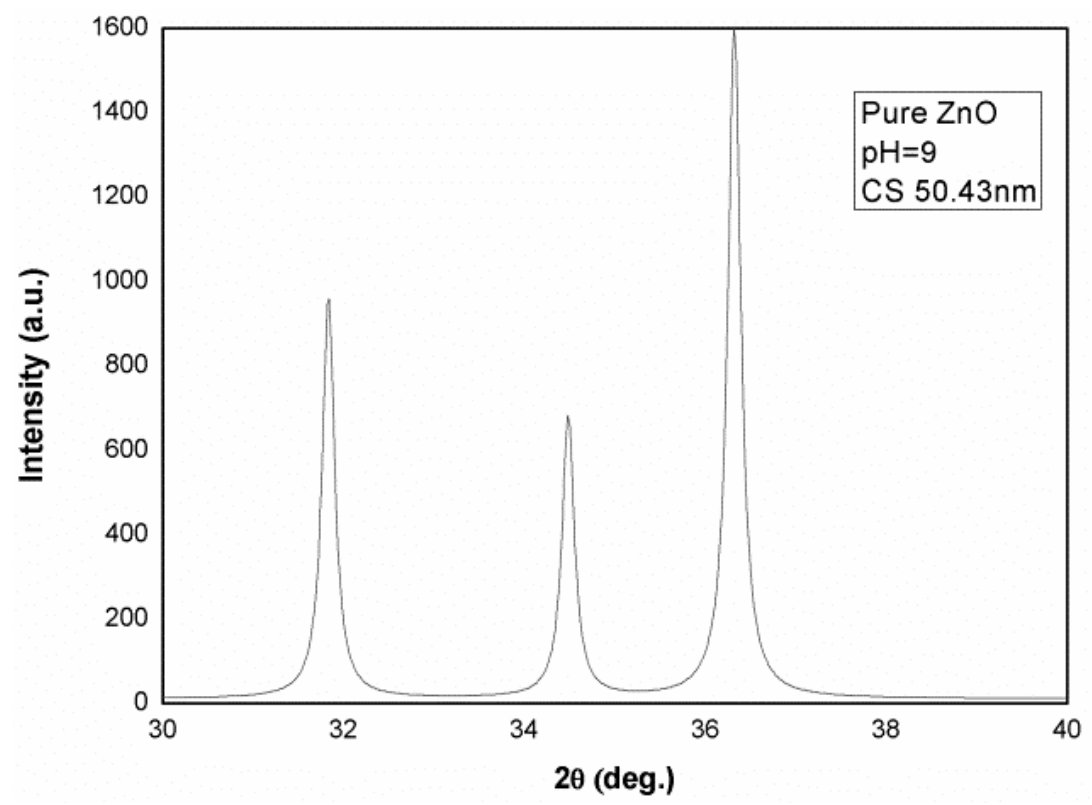

Fig. (1). XRD of $\mathrm{ZnO}$ nanoparticles.

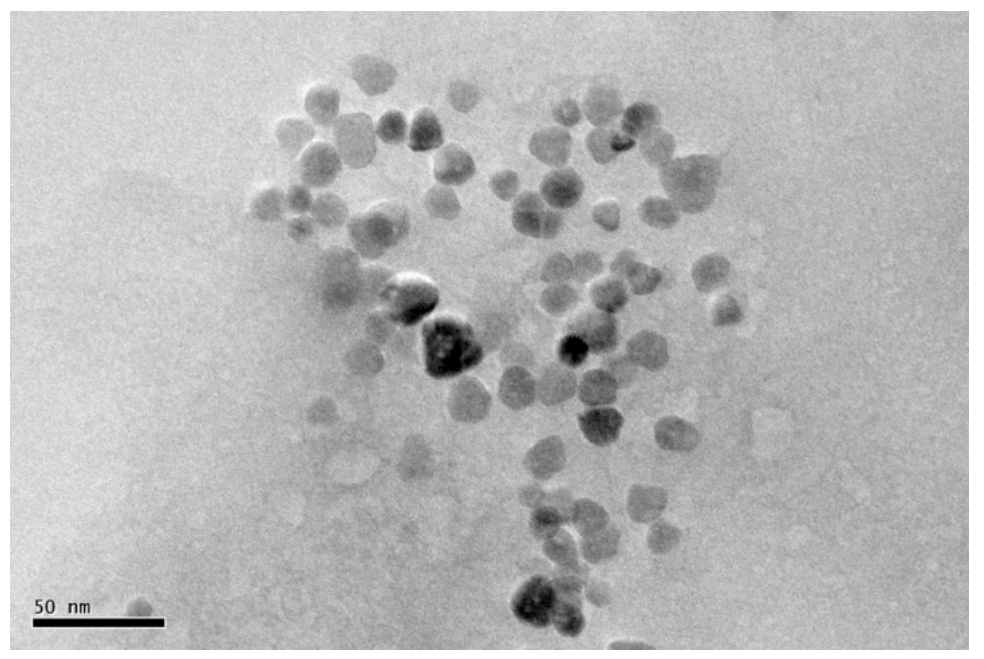

Fig. (2). TEM of $\mathrm{ZnO}$ particles.

was grounded by a mortar and pestle with $4 \mathrm{ml}$ deionised water, and polyethylene glycol( $\left(\mathrm{PEG}_{20,000}, .0 .5 \mathrm{gm}\right)$ to break up the aggregated particles into a dispersed paste [14]. The paste was spread on the surface of conducting substrate with a glass rod. After drying in the air the films were sintered for 30 minutes at $400^{\circ} \mathrm{C}$ in air. The resulting film was immersed in a $3.0 \times 10^{-4} \mathrm{M}$ solution of acridine orange dye in ethanol for 24 hours. To minimise adsorption of impurities from moisture in the ambient air, the electrode was dipped in the dye solution while they were still warm $\left(80^{\circ} \mathrm{C}\right)$. The dye covered electrodes were then rinsed with ethanol to remove excess dye on the surface and dried at room temperature. A sandwich-type DSSC was fabricated with dye sensitised electrode, a thin platinum sheet as counter electrode and an electrolyte as spacer.

\subsection{Electrochemical Impedance Spectroscopy (EIS) \& Equivalent Circuit}

Electrochemical impedance spectroscopy (EIS) has been used to analyze internal resistance of DSSC and three internal resistances have been found. [8, 9]. In Plot of DSSC three semicircles are observed in the frequency range of $10^{-1}$ $-10^{6} \mathrm{~Hz}$ which correspond to three types of impedance namely Z1, Z2 and Z3. Z1 is related to charge transport at the $\mathrm{Pt}$ counter electrode in the high frequency ( $\mathrm{KHz}$ range) region. $\mathrm{Z} 2$ is the impedance observed in middle frequency $(10-100 \mathrm{~Hz})$ region at $\mathrm{TiO} 2 /$ dye/ electrolyte interface. Impedance $Z 3$ due to Nernstian diffusion is prominent in low frequency $(\mathrm{m} \mathrm{Hz})$ region. [8]. Origin of $\mathrm{Z1}$ and $\mathrm{Z3}$ are similar to those reported by Kern et al. [5]. Han L et al. [8] proved that $\mathrm{Z2}$ is impedance of diode.

EIS of a DSSC prepared at our centre having $\mathrm{ZnO}$ as electrode and platinum as counter electrode using potentiostat (Gamry potentiostat and analyzer) also showed similar results as shown in Fig. (3).

Hence it can be concluded that the DSSC model consists of series, shunt resistive and capacitive parts. $Z_{1}$ is parallel combination of $\mathrm{R} 1$ and $\mathrm{C}_{1}, \mathrm{Z}_{2}$ is parallel combination of $\mathrm{R}_{2}$ and $C_{2}$, and $Z_{3}$ is parallel combination of $R_{3}$ and $C 3$. From EIS plot order of $C_{1}$ is estimated to be 2.0 to $14.0 \mu \mathrm{F}$ and $C_{2}$ from 0.3 to $70 \mathrm{mF}$. 


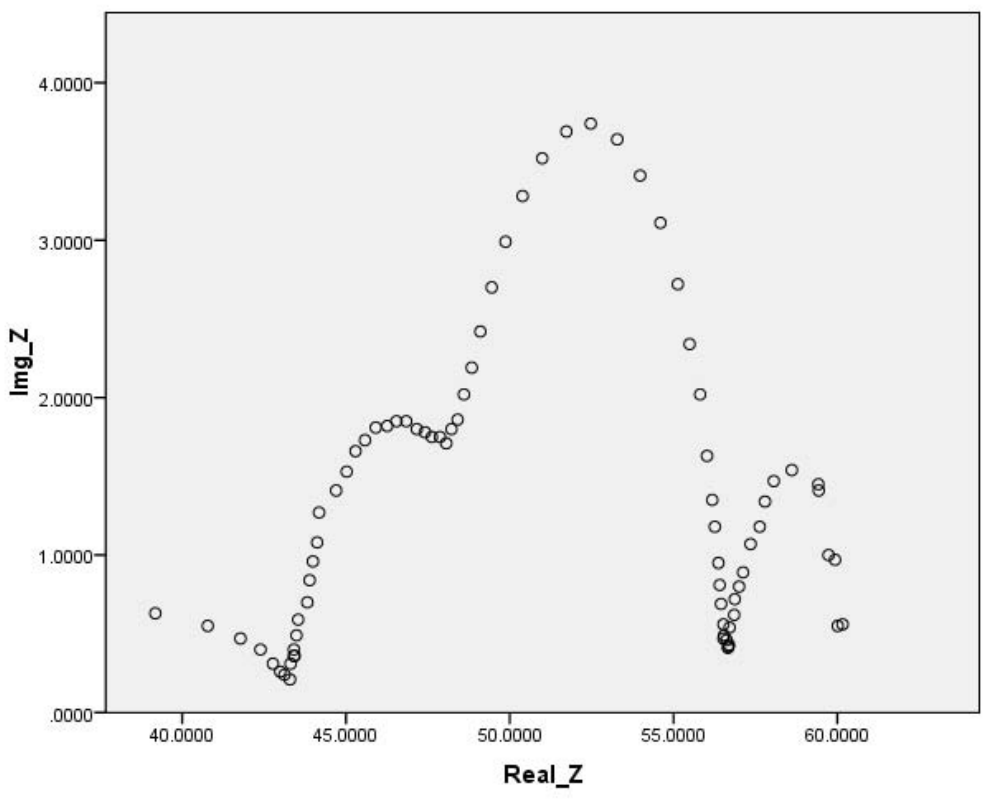

Fig. (3). EIS of DSSC.

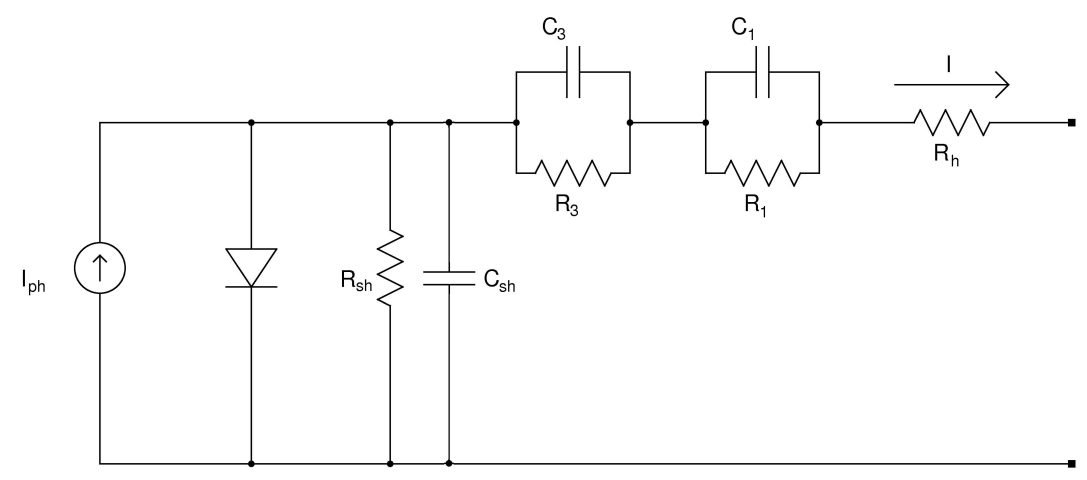

Fig. (4a). Equivalent circit of DSSC.

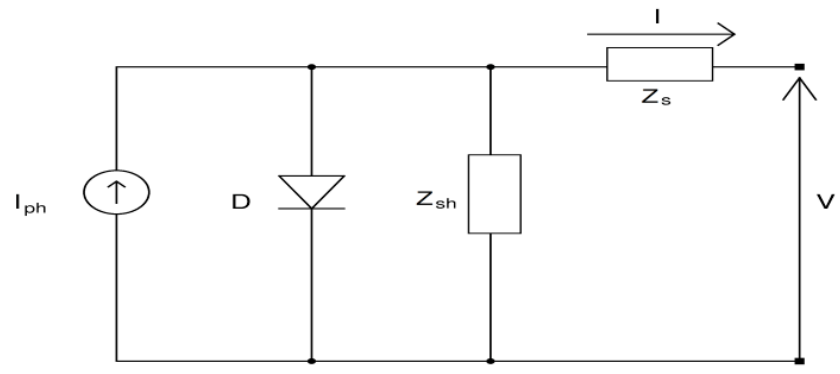

Fig. (4b). simplified equivalent circuit of DSSC.

Equivalent circuit of dye sensitized solar cell (DSSC) is shown in Fig. (4a, 4b).

\subsection{Theoretical Analysis}

Single diode model for DSSC including capacitance was taken into consideration to derive the current voltage relation. The equation of equivalent circuit can be written as:

$\mathrm{i}=\mathrm{i}_{\mathrm{ph}}-\mathrm{i}_{\mathrm{o}}\left(\mathrm{e}^{\frac{\mathrm{V}+\mathrm{iZ}}{\mathrm{nK}}}-1\right)-\frac{\mathrm{V}+\mathrm{i} \mathrm{Z}_{\mathrm{s}}}{\mathrm{Z}_{\mathrm{sh}}}$
Where $\mathrm{K}=\mathrm{kT} / \mathrm{q}$.

In this equation $i_{\text {ph }}$ represents photocurrent, $i_{0}$ Initial current, $Z_{\mathrm{s}}$ series resistance $Z_{\mathrm{sh}}$ shunt resistance, $n$ ideality factor, q elementary electric charge, $\mathrm{k}$ Boltzmann constant and $\mathrm{T}$ temperature, $Z_{\mathrm{s}}$ and $Z_{\mathrm{sh}}$ contains both resistance and capacitance.

Mathematical expressions for $Z_{\mathrm{s}}$ and $Z_{\mathrm{sh}}$ are:

$Z_{s}=\frac{R_{s}\left(1-I \omega C_{s} R_{s}\right)}{1+\omega^{2} R_{s}^{2} C_{s}^{2}}$ 


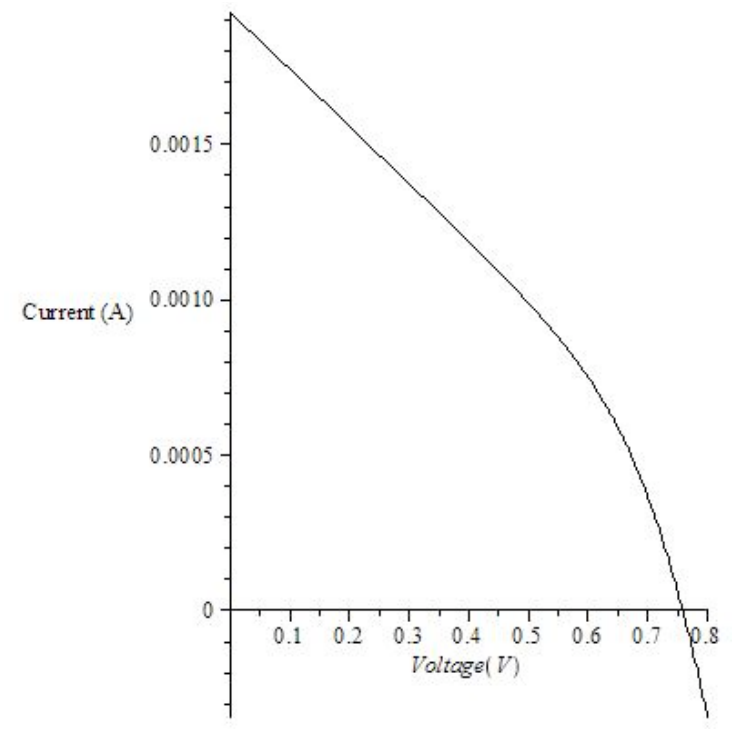

Fig. (5). I-V curve of DSSC.

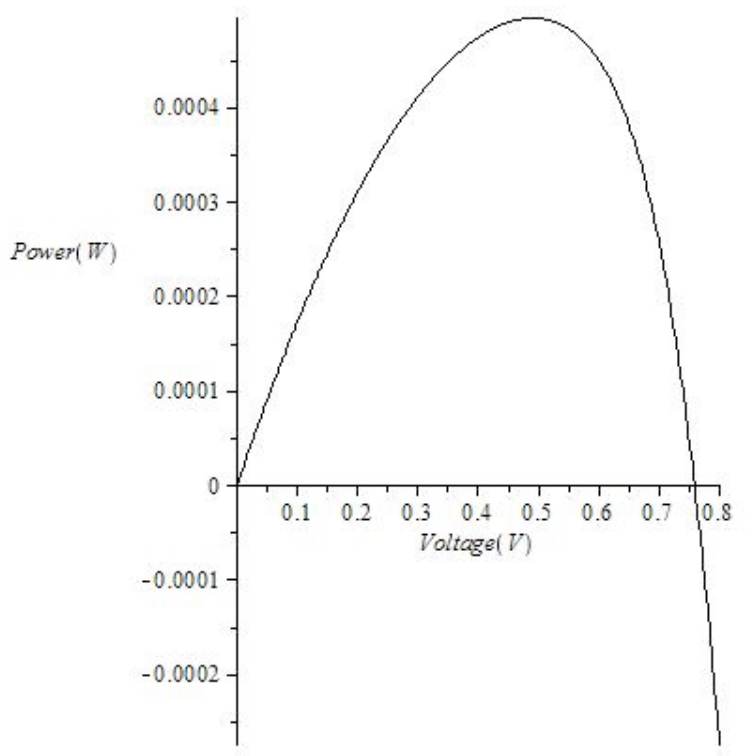

Fig. (6). P-V curve of DSSC.

$Z_{\text {sh }}=\frac{R_{s h}\left(1-I \omega R_{s h} C_{s h}\right)}{1+\omega^{2} R_{s h}^{2} C_{s h}^{2}}$

Equation (1) is transcendental in nature hence it is not possible to solve it explicitly. The explicit solution for current and voltage can be expressed using Lambert $\mathrm{W}$ function $[11,15]$.

$$
\begin{aligned}
& V=-i Z_{s}-i Z_{s h}+i_{p h} Z_{s h}-n K \text { LambertW }\left(\frac{i_{o} Z_{s h} e^{-\frac{Z_{s h}\left(i-i_{p h}-i_{0}\right)}{n K}}}{n K}\right)+i_{o} Z_{s h} \\
& i=-\frac{V}{Z_{s}}+\frac{1}{Z_{s}}\left(\left(- \text { LambertW }\left(\frac{Z_{s} i_{o} Z_{s h} e^{\frac{Z_{s h}\left(Z_{s p h}+Z_{s} i+v\right)}{n K\left(Z_{s h}+Z_{s}\right)}}}{Z_{s} n K+Z_{s h} n K}\right)\right.\right. \\
& \left.+\frac{Z_{s h}\left(Z_{s} i_{p h}+Z_{s} i_{o}+V\right)}{n K\left(Z_{s h}+Z_{s}\right)}\right) n K
\end{aligned}
$$

Expression for open circuit voltage and short circuit current can be obtained by substituting $\mathrm{i}=0$ in eq. 2 and $\mathrm{V}=0$ in eq.3:

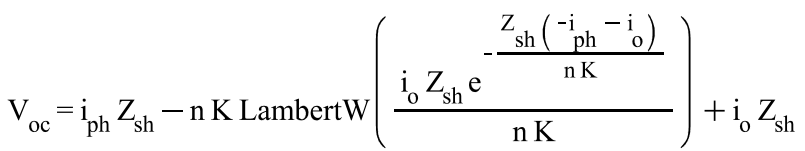

$i_{s c}=\frac{\left(- \text { LambertW }\left(\frac{Z_{s} i_{o} Z_{s h} e^{\frac{Z_{s h}\left(Z_{s p h}+Z_{s o}\right)}{n K\left(Z_{s h}+Z_{s}\right)}}}{Z_{s} n K+Z_{s h} n K}\right)+\frac{Z_{s h}\left(Z_{s} i_{p h}+Z_{s} i_{o}\right)}{n K\left(Z_{s h}+Z_{s}\right)}\right) n K}{Z_{s}}$

Expressions for calculating maximum power point are:

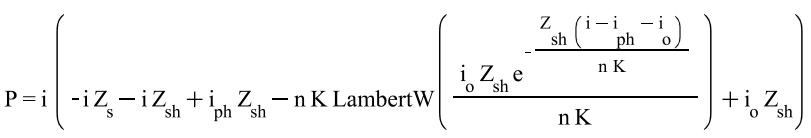

and

$$
\begin{aligned}
P= & \frac{1}{Z_{s}}\left(-V^{2}+\left(-L a m b e r t W\left(\frac{Z_{s} i_{o} Z_{s h} e^{\frac{Z_{s h}\left(Z_{s p h}+Z_{s o}+V\right.}{n K}\left(Z_{s h}+Z_{s}\right)}}{Z_{s} n K+Z_{s h} n K}\right)\right.\right. \\
+ & \left.\frac{Z_{s h}\left(Z_{s} i_{p h}+Z_{s} i_{o}+V\right)}{n K\left(Z_{s h}+Z_{s}\right)}\right)
\end{aligned}
$$

To achieve maximum power points the first partial derivatives of power w.r.t current and voltage should be set equal to zero $[11,15]$ : Using explicit solutions of current voltage relations of DSSC (that includes capacitance) different parameters were extracted viz. $\mathrm{I}_{\mathrm{sc}}, \mathrm{V}_{\mathrm{oc}}, \mathrm{I}_{\max }, \mathrm{V}_{\max }$. The respective values of extracted parameters are;

$$
\mathrm{I}_{\mathrm{sc}}=0.0019238, \mathrm{Voc}=0.758651, \mathrm{I}_{\max }=0.00101, \mathrm{~V}_{\max }=
$$
0.490194 . I-V and P-V curves were also plotted using Wfunction results (Fig. 5 and $\mathbf{6}$ ).

\section{MATLAB SIMULATION}

Availability of PV module-simulator in MATLAB platform is a tool of immense advantage for researchers as MATLAB has become a de-facto standard in various researches and engineering disciplines. Besides having better accuracy this simulator is simple and fast, making it a perfect choice for analyzing behaviour of different solar cells including DSSC. The input parameters for the simulation in present work are $I_{s c}$, Voc, $I_{m}$ and $V_{m}$. Using the values of these parameters obtained from $\mathrm{W}$-function technique, static and dynamic I-V, P-V, curves are plotted using PV modulesimulator in MATLAB Fig. $(\mathbf{7}, \mathbf{8})$. The dynamic behaviour in the Fig. $(7,8)$ is expressing the $\mathrm{I}-\mathrm{V}$ characteristics taking capacitive effects of DSSC while static one are without considering them. It is from the curves that maximum power point (PV) changes with taking capacitive effects in mathematical model of DSSC. The same has been observed analytically using Maple and by simulation using MATLAB. The effect can be explained by charging, discharging of various capacitances present in the DSSC (equivalent circuit). 


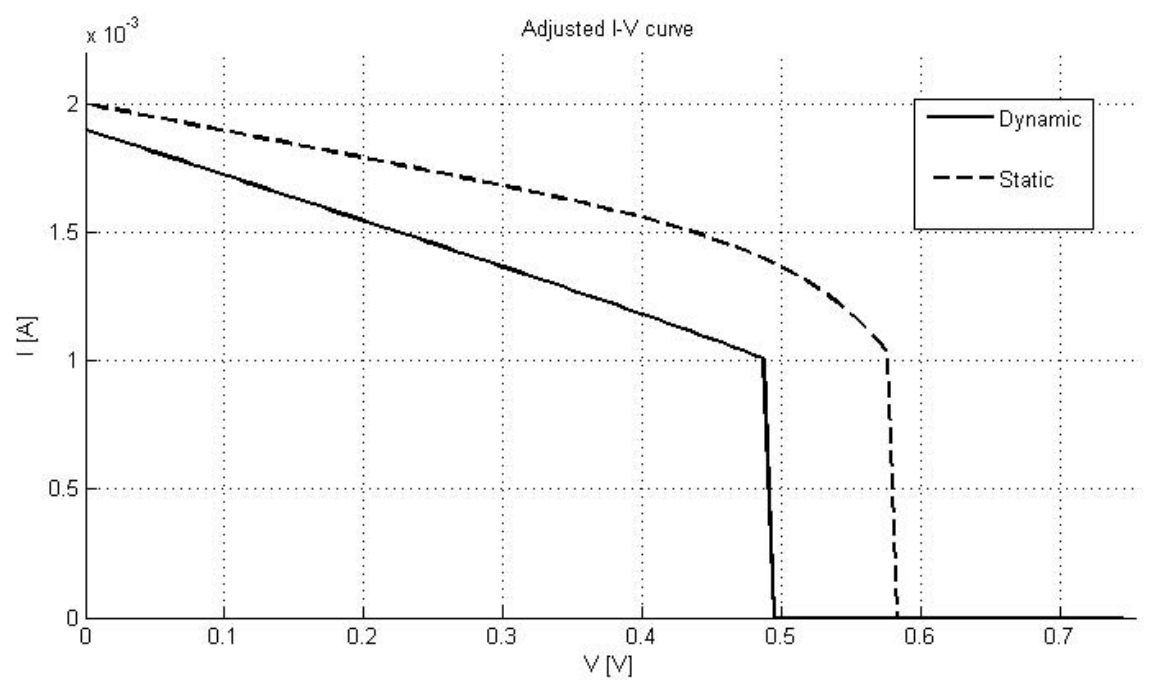

Fig. (7). Simulated I-V curves of DSSC.

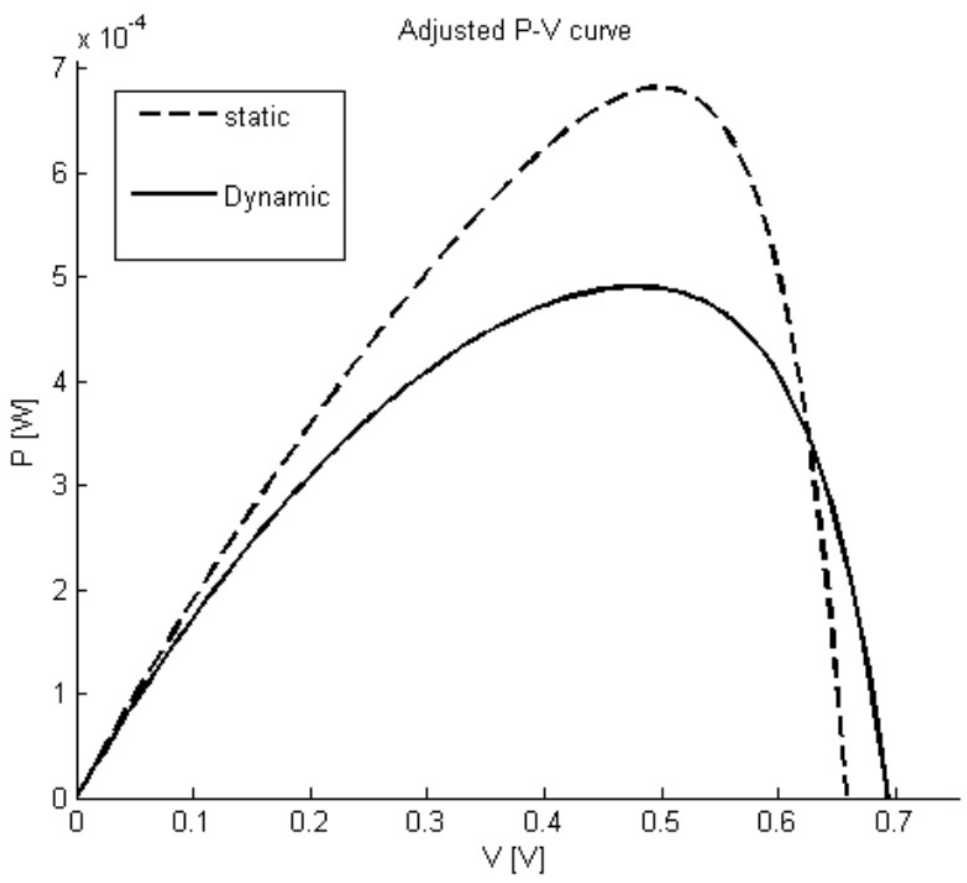

Fig. (8). Simulated P-V curves of DSSC.

\section{DISCUSSION AND CONCLUSION}

The existence of double charged layer at semiconductor and electrolyte interface leads to capacitance characteristics. The presence of capacitance in DSSC was confirmed by EIS. The traditional IPCE measurement method of solar cell is not applicable to DSSC because of its capacitance characteristics. The effect of capacitance on output characteristic is analytically proved by Lambert $\mathrm{W}$-function technique and validated by MATLAB Simulation as reflected in I-V and P-V curves with good accuracy. Present article can be extended to study detailed analysis of capacitive effects of capacitance in various solar cells and hence can lead to better understanding of internal mechanisms in solar cells.

\section{CONFLICT OF INTEREST}

The authors confirm that this article content has no conflicts of interest.

\section{ACKNOWLEDGEMENTS}

1. Authors express sincere gratitude and indebtedness to Dr. Prerna Gaur, Netaji Subhash Institute of Technology, Delhi; for providing us with her invaluable help and inputs.

2. Authors also thank Dr. Vandana, National Physical Laboratories Delhi; for her support in providing us 
with the requisite resources, essential for carrying out the research work.

\section{REFERENCES}

[1] Gratzel, M. Dye-sensitized solar cell. J. Photochem. Photobiol. C Photochem Rev., 2003, 4, 145-153

[2] Murayama, M.; Mori, T. Equivalent circuit analysis of dye sensitized solar cell by using one diode model: effect of Carboxylic acid treatment of TiO2 electrode. Jpn. J. Appl. Phys., 2006, 45 (1B), $542-545$

[3] Koide, N. \& Han, L. Measuring methods of cell performance of dye-sensitized solar cells. Rev. Sci. Instrum., 2004, 75, 2828-2831

[4] Chen Shuanghong,W.J.; Dai,S.;Yufeng, H.; Wang, K. The investigation of measurement of dye sensitized solar cell. Acta Energiae Solaris Sin., 2006, 9, 900-904

[5] Kern, R.; Sastrawan, R.; Ferber, J.; Stagnl, R.; Luther, J. Modeling and interpretation of electrical impedance spectra of dye solar cell under open circuit conditions, Electrochim. Acta, 2002, 47, 42134225

[6] Kumar, R. A.; Suresh, M. S; Nagaraju, J. Time domain technique to measure solar cell capacitance. Rev Sci Instrum 2003 , 74, 35163519

[7] Hanmin, T.; Jiyuan, Z.; Xiangyan, W.; Tao, Y.; Zhigang, Z. Influence of capacitance characteristic on I-V measurement of dyesensitized solar cell. Measurement, 2011, 44, 1551-1555.
[8] Han, L.; Koide, N.; Chiba, Y.; Mitate, T. Modeling of an equivalent circuit for dye-sensitized solar cells. Appli. Phys. Let., 2004, 84 (13), 2433-2435

[9] Han, L.; Koide, N.; Chiba, Y.; Islam, A.; Mitate,T. Modeling of equivalent circuit for dye sensitized solar cells: improvement of efficiency of dye-sensitized solar cell by reducing internal resistance C. R. Chime, 2006, 9, 645-651

[10] Merhej, P.; Dallago, E.; Finarelli, D. Effect of capacitance on output characteristics of solar cells. Proceed Microelectron Electron Berlin 2010

[11] Guliani, R.; Jain, A.; Kapoor, A. Exact analytical analysis of Dye Sensitized Solar Cell: Improved method and comparative Study. Open Renew Energy J., 2012, 5, 49-60

[12] Ishaque,K.; Salam,Z.; Taheri,H. Accurate MATLAB simulink PV system simulator based on Two-Diode model. J. Power Electron 2011, 11(2), 179-187

[13] Singh, N.; Dhruvashi; Kaur, D.; Mehra, R.M.; Kapoor,A. effect of ageing in structural properties of $\mathrm{ZnO}$ nanoparticles with ph variation for application in solar cells. Open Renew Energy $J$ 2012, 5, $15-18$

[14] Rani, S.; Suri, P.; Shishodia, P. K.; Mehra, R. M. Synthesis of nanocrystalline $\mathrm{ZnO}$ powder via sol-gel route for dye-sensitized solar cells. Solar Energy Mater Solar Cells, 2008, 92, 1639-1645

[15] Jain, A.; Kapoor, A. Exact Analytical solution of the parameters of real solar cells Lambert W-function, Solar Energy Mater and Solar Cells, 2004, 81, 269-277.

(C) Guliani et al.; Licensee Bentham Open.

This is an open access article licensed under the terms of the Creative Commons Attribution Non-Commercial License (http://creativecommons.org/licenses/by-nc/3.0/) which permits unrestricted, non-commercial use, distribution and reproduction in any medium, provided the work is properly cited. 